\title{
Impact of 6:2 fluorotelomer alcohol aerobic biotransformation on a sediment microbial community
}

\author{
Shu Zhang ${ }^{\mathrm{a}, 1}$, Nancy Merino ${ }^{\mathrm{b}}$, Ning Wang ${ }^{\mathrm{c}, *}$, Ting Ruan ${ }^{\mathrm{d}, * *}$, Xiaoxia Lu $^{\mathrm{a}, *}$ \\ ${ }^{a}$ Laboratory for Earth Surface Processes, Ministry of Education, College of Urban and Environmental Sciences, Peking University, Beijing 100871, China \\ b Earth-Life Science Institute, Tokyo Institute of Technology, Ookayama, Meguro-ku, Tokyo 152-8550, Japan \\ c 132 Shrewsbury Dr., Wilmington, DE 19810, USA \\ d State Key Laboratory of Environmental Chemistry and Ecotoxicology, Research Center for Eco-Environmental Sciences, Chinese Academy of Sciences, Beijing 100085, China
}

\section{H I G H L I G H T S}

- 6:2 FTOH was rapidly biotransformed in river sediment at both $5 \mathrm{mg} / \mathrm{L}$ and $15 \mathrm{mg} / \mathrm{L}$ doses.

- 6:2 FTOH and its major transformation products in the sediment impacted microbial taxonomic distribution and diversity.

- Proteobacteria, Chloroflexi and Verrucomicrobia were the dominant microbes in the sediment.

\section{G R A P H I C A L A B S T R A C T}

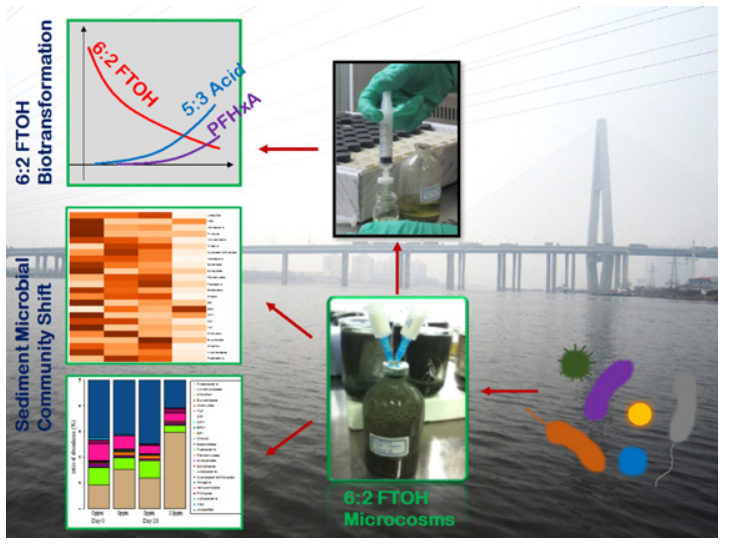

\section{A R T I C L E I N F O}

\section{Article history:}

Received 13 August 2016

Received in revised form 26 September 2016

Accepted 27 September 2016

Available online 15 October 2016

Editor name: Jay Gan

\section{Keywords:}

Polyfluoroalkyl substances

Microcosms

16S rRNA gene amplicon sequencing

Microbial community analysis

Proteobacteria

\begin{abstract}
A B S T R A C T
Sediment microbial communities are responsible for many chemical biotransformation processes in the aquatic environment and play a critical role in various ecosystems and biogeochemical cycling. However, the impact of polyfluoroalkyl substances on sediment microbial communities remains unclear. These substances are increasingly being used in consumer and industrial products to replace environmentally persistent perfluoroalkyl substances. In this study, we investigated the effects of low $(5 \mathrm{mg} / \mathrm{L})$ and high $(15 \mathrm{mg} / \mathrm{L})$ doses of $6: 2$ fluorotelomer alcohol [6:2 FTOH, $\left.\mathrm{F}\left(\mathrm{CF}_{2}\right)_{6} \mathrm{CH}_{2} \mathrm{CH}_{2} \mathrm{OH}\right]$ on the structure of a sediment microbial community. 6:2 FTOH biotransformation was rapid in the sediment mixture with a half-life $<3$ days, regardless of the initial doses. After 28 days, major products produced in the high dose condition included $28 \mathrm{~mol} \% 5: 2 \mathrm{sFTOH}\left[\mathrm{F}\left(\mathrm{CF}_{2}\right)_{5} \mathrm{CH}(\mathrm{OH}) \mathrm{CH}_{3}\right], 9.6 \mathrm{~mol} \%$

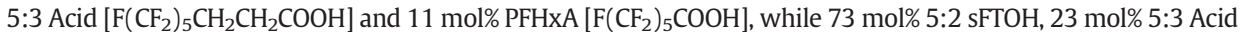
and $26 \mathrm{~mol} \% \mathrm{PFHxA}$ were observed in the low dose condition. In the original (control) sediment without 6:2 FTOH dosing, Proteobacteria was the predominant microorganism (18\%), followed by Chloroflexi (14\%), Verrucomicrobia (13\%), Firmicutes (3.4\%), Bacterioidetes (2.4\%), Actinobacteria (1.7\%) and Planctomycetes (1.3\%). The presence of 6:2 FTOH and the accumulation of transient transformation products in the sediment
\end{abstract}

\footnotetext{
* Corresponding authors.

** Correspondence to: T. Ruan, Research Center for Eco-Environmental Sciences, Chinese Academy of Sciences, Beijing 100085, China.

E-mail addresses: nwang.2@verizon.net (N. Wang), tingruan@rcees.ac.cn (T. Ruan), luxx@urban.pku.edu.cn (X. Lu).

${ }^{1}$ Current address: Department of Civil and Environmental Engineering, University of California, Los Angeles, CA 90095, USA.
} 
exerted selection pressure on the microbial taxonomic distribution and diversity. Our observations indicate that potential 6:2 FTOH degraders and tolerant strains, such as Dokdonella spp., Thauera spp., Albidovulum spp. and Caldanaerovirga spp., existed in the sediment mixture and began to dominate over time. This suggests that these genera might have higher tolerance towards elevated 6:2 FTOH and its transformation products. These findings on the characterization of sediment microbial community stability and dynamics will help predict changes in response to perfluoroalkyl and polyfluoroalkyl substances and also help identify robust microbial strains to degrade polyfluoroalkyl substances in the environment.

(c) 2016 Elsevier B.V. All rights reserved.

\section{Introduction}

6:2 fluorotelomer alcohol [6:2 FTOH, $\mathrm{F}\left(\mathrm{CF}_{2}\right)_{6} \mathrm{CH}_{2} \mathrm{CH}_{2} \mathrm{OH}$ ], along with its analogs $\left[\mathrm{F}\left(\mathrm{CF}_{2}\right)_{6} \mathrm{CH}_{2} \mathrm{CH}_{2}-\mathrm{X}\right]$, constitutes a major class of polyfluoroalkyl substances (PFASs) with unique hydrophobic and oleophobic properties that were used to replace long-chain PFASs ( $\geq 7$ perfluorinated carbons) (Buck et al., 2011; Kissa, 2001). Specifically, 6:2 FTOH and its structural analogs are the major alternatives to replace 8:2 FTOH and have been widely used to manufacture 6:2 FTOH-based surfactants and polymer products for industrial and consumer applications (Ritter, 2015), such as coatings and repellents in packages, textiles, lubricants, and paints (Buck et al., 2011; Yao et al., 2016). A recent study on the occurrence of FTOH in food-contact materials(FCMs) indicated that most detected FCMs produced in the U.S. were dominated by $6: 2$ FTOH, following by 8:2 FTOH and 10:2 FTOH (Yuan et al., 2016). PFASs, including 6:2 FTOH analogs, are also important components in aqueous film-forming foams (AFFFs) and electronics (Buck et al., 2011; Kissa, 2001). Application of PFASs in consumer and industrial products has led to increasing PFAS concentrations in the environment and human exposure (Ellis et al., 2004; Liu and Mejia Avendaño, 2013; Merino et al., 2016b; Tian et al., 2016; Yao et al., 2016; Yuan et al., 2016). Specifically, abiotic and biotic transformation of 6:2 FTOH in soil, sediment, and activated sludge can contribute to poly- and perfluorinated carboxylates (PFCAs) in the environment (Ellis et al., 2004; Liu et al., 2010b; Zhang et al., 2013; Zhao et al., 2013). 6:2 FTOH mammalian toxicity was described previously (Russell et al., 2015; Serex et al., 2014).

Previous studies on 6:2 FTOH biotransformation mainly focused on the microbial biodegradation pathways and identification of novel transformation products (Liu and Mejia Avendaño, 2013; Butt et al., 2014). 6:2 FTOH aerobic biotransformation in soil, sediment, and activated sludge formed 5:2 sFTOH as the major transient transformation product, and 5:3 Acid, PFPeA [ $\left.\mathrm{F}\left(\mathrm{CF}_{2}\right)_{4} \mathrm{COOH}\right], \mathrm{PFHxA}$, and PFBA [F( $\left.\left.\mathrm{CF}_{2}\right)_{3} \mathrm{COOH}\right]$ as the major stable products (Liu et al., 2010a, b). 6:2 FTOH and its aforementioned major transformation products have been found in the environment (Dreyer et al., 2009; Wang et al., 2014) and are likely to impact local microbial communities. However, no information is available on how microbial communities are affected by the presence of 6:2 FTOH and its transformation products and only one study (Sun et al., 2016) is available on the impact of perfluoroalkyl acids (PFAAs) on microbial community composition and dynamics in sediment.

Currently, high-throughput sequencing is a common and robust tool to identify microbial composition and to characterize microbial community stability and dynamics (Delmont et al., 2015; Faust et al., 2015). These methods have been ubiquitously applied for the human microbiome and in the food industry, pharmaceutical applications and environmental microbiology (David et al., 2015; Hsu et al., 2016; Mackelprang et al., 2011; Vaishampayan et al., 2010). They have provided more information on the impacts of organic chemicals on microbial communities and have helped with the isolation of novel microbial degraders and pollutant indicators (David et al., 2015). A recent study showed that in sediments contaminated with high perfluorooctanoic acid (PFOA) concentrations, the microbial community was likely impacted by PFOA and shifted towards increasing abundance of Proteobacteria, $\varepsilon$-Proteobacteria, Thiobacillus and Sulfurimonas (Sun et al., 2016). Yet, studies on the impacts of polyfluorinated compounds in natural microbial system via microbial community analysis are still scarce.

The objective of this study was to investigate the effects of $6: 2 \mathrm{FTOH}$ on the microbial community structure of subsurface sediment via $16 \mathrm{~S}$ rRNA gene amplicon sequencing. As earlier studies addressed, the sediment microbial system is highly diverse, containing aerobic and anaerobic microorganisms (Sinclair and Ghiorse, 1989; Wang et al., 2012). Our study focused on the aerobic microbial activity of 6:2 FTOH transformation. Environmental microcosms were established to evaluate the biotransformation of low and high concentrations of 6:2 FTOH in a river sediment mixture from China and examined temporal variations of the microbial community taxonomy. This is the first attempt to investigate the influence of $6: 2 \mathrm{FTOH}$ on a sediment microbial community over time via 16S rRNA gene amplicon sequencing.

\section{Materials and methods}

\subsection{Chemicals}

The polyfluoroalkyl and perfluoroalkyl substances used in this study are listed in Table S1 with chemical names, acronyms and molecular structures in the supplemental materials. Chemicals 6:2 FTOH, PFBA, PFPeA, PFHxA and PFHpA [F( $\left.\left(\mathrm{CF}_{2}\right)_{6} \mathrm{COOH}\right]$ were purchased from SigmaAldrich (St. Louis, MO). 5:2 Ketone $\left[\mathrm{F}\left(\mathrm{CF}_{2}\right)_{5} \mathrm{C}(\mathrm{O}) \mathrm{CH}_{3}\right]$ was purchased from TCI America (Portland, OR). 6:2 FTCA [F( $\left.\left(\mathrm{CF}_{2}\right)_{6} \mathrm{CH}_{2} \mathrm{COOH}\right], 6: 2$ FTUCA $\left[\mathrm{F}\left(\mathrm{CF}_{2}\right)_{5} \mathrm{CF}=\mathrm{CHCOOH}\right], 5: 2 \mathrm{sFTOH}, 5: 3$ Acid, 4:3 Acid [F( $\left.\left.\mathrm{CF}_{2}\right)_{4} \mathrm{CH}_{2} \mathrm{CH}_{2} \mathrm{COOH}\right], 5: 3$ Uacid $\left[\mathrm{F}\left(\mathrm{CF}_{2}\right)_{5} \mathrm{CH}=\mathrm{CHCOOH}\right], \alpha-\mathrm{OH}$ 5:3 Acid $\left[\mathrm{F}_{(}\left(\mathrm{CF}_{2}\right)_{5} \mathrm{CH}_{2} \mathrm{CH}(\mathrm{OH}) \mathrm{COOH}\right]$ were synthesized by DuPont (Wilmington, DE). The purity of the chemicals used in this study is $97 \%$ or higher. The ${ }^{13} \mathrm{C}$ labeled internal standards used for liquid chromatography tandem mass spectrometry (LC-MS/MS) quantitative analysis were $\left[1,1,2,2-\mathrm{D} ; 3^{-13} \mathrm{C}\right] 6: 2 \mathrm{FTOH}\left[\mathrm{F}\left(\mathrm{CF}_{2}\right)_{5}^{13} \mathrm{CF}_{2} \mathrm{CD}_{2} \mathrm{CD}_{2} \mathrm{OH}\right]$ (DuPont, Wilmington, DE) and $\left[1,2-{ }^{13} \mathrm{C}\right] \mathrm{PFHxA}\left[\mathrm{F}\left(\mathrm{CF}_{2}\right)_{4}^{13} \mathrm{CF}_{2}^{13} \mathrm{COOH}\right]$ (Wellington Laboratories, Ontario, Canada). C18 cartridges (600 mg sorbent) were obtained from Alltech (Deerfield, IL). Acetonitrile and other solvents were purchased from Sinopharm Chemical Reagent Beijing Co., Ltd. (HPLC grade or higher). De-ionized water $(18 \mathrm{M} \Omega-\mathrm{cm})$ was generated by Milli-Q system (Millipore, Billerica, MA).

\subsection{Sediment collection}

Fresh surface sediment ( $<5 \mathrm{~m}$ depth) and river water were sampled from Hai River in Tianjin, China in December of 2012. The geographic information of the sampling location and chemical parameters were previously reported (Lu et al., 2013). Sediment samples were collected in zip-lock bags with enough headspace for aeration and river water was saved in polypropylene containers. All samples were stored in a cooler during transportation and were kept at $4{ }^{\circ} \mathrm{C}$ in the laboratory before being processed. Microcosm studies were initiated using a sediment mixture (volume ratio of sediment to river water was approximately 2:3) within one week after sampling. 


\subsection{Aerobic biotransformation in river sediment}

To determine the impact of 6:2 FTOH and its major transformation products on sediment microbial community dynamics and changes, a 6:2 FTOH biotransformation experiment was performed following the procedures that have been previously well established and validated (Liu and Mejia Avendaño, 2013; Zhao et al., 2013). Briefly, the 6:2 FTOH biotransformation experiment provided information on the kinetics of major transformation product formation to help determine sampling times for microbial community analysis. Each experimental vessel (120-mL glass serum bottle) was filled with $25 \mathrm{~mL}$ sediment mixture and $5 \mathrm{~mL}$ mineral medium ( $\mathrm{pH}$ 7.0). The mineral medium

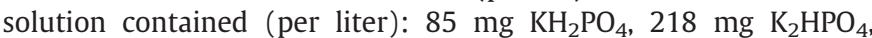
$334 \mathrm{mg} \mathrm{Na} 2 \mathrm{HPO}_{4} \cdot 2 \mathrm{H}_{2} \mathrm{O}, 5 \mathrm{mg} \mathrm{NH} \mathrm{Cl}_{4}, 36.4 \mathrm{mg} \mathrm{CaCl} \cdot 2 \mathrm{H}_{2} \mathrm{O}, 22.5 \mathrm{mg}$ $\mathrm{MgSO}_{4} \cdot 7 \mathrm{H}_{2} \mathrm{O}$, and $0.25 \mathrm{mg} \mathrm{FeCl} \cdot 6 \mathrm{H}_{2} \mathrm{O} .6: 2 \mathrm{FTOH}$ stock solutions $(0,8$ and $24 \mathrm{~g} / \mathrm{L}$, respectively) were made in $10 \mathrm{~mL}$ glass bottles containing $50 \%$ ethanol $(\mathrm{v} / \mathrm{v}$, ethanol:water $=1: 1)$ and stored at $4{ }^{\circ} \mathrm{C}$. For different live sediment conditions, different $20 \mu \mathrm{L}$ stock solutions were dosed to achieve final 6:2 FTOH concentrations of around 0,5 and $15 \mathrm{mg} / \mathrm{L}$, respectively (Calculation of the concentrations were shown in Supplementary Materials). An earlier study reported the range of PFSAs in contaminated groundwater was from 0.018 to $7.09 \mathrm{mg} / \mathrm{L}$. Recent work on the toxicokinetics of $6: 2 \mathrm{FTOH}$ also examined the concentrations of $0.5,5$ and $10 \mathrm{ppm}$ and its effects mammals due to inhalation, suggesting the relevance and importance of high concentrations (Moody and Field, 1999; Russell et al., 2015). Each bottle was closed with a grey butyl rubber stopper and crimped with aluminum cap immediately after adding 6:2 FTOH. To ensure aerobic conditions and to capture volatile metabolites, two $\mathrm{C} 18$ cartridges were connected to the headspace of each bottle by an 18-gauge needle punctured through the stopper. Previous studies have demonstrated that C18 cartridges can allow for enough passage of air to maintain aerobic conditions. For instance, using similar experimental construction, Kim et al. (2012) demonstrated that sufficient oxygen $(>10 \%)$ remained in the headspace to maintain the aerobic condition during 28 days. In an experimental system using fungal cultures, Tseng et al. (2014) also reported that oxygen content (>19\%) can stabilize over 28 days. For the sterile control, closed bottles with river sediment mixture were autoclaved for $45 \mathrm{~min}$ before 6:2 FTOH was dosed and $\mathrm{C} 18$ cartridges were introduced into the headspace of the bottles. An additional $0.75 \mathrm{~mL}$ of $1 \mathrm{M} \mathrm{HCl}$ was added to each sterile bottle to prevent microbial growth in the sediment mixture during incubation. All sample bottles were kept upright and agitated continuously at about $150 \mathrm{rpm}$ on an orbital shaker at room temperature at approximately $20-25^{\circ} \mathrm{C}$.

At days $0,3,7,14$ and 28 , one bottle of each condition was stored at $-20^{\circ} \mathrm{C}$ for DNA extraction and $16 \mathrm{~S}$ rRNA gene amplicon sequencing. In parallel, sacrificial sampling of each condition (one unexposed bottle, two $5 \mathrm{mg} / \mathrm{L}$ live bottles, one $15 \mathrm{mg} / \mathrm{L}$ live bottle and two sterile bottles) was conducted for quantifying 6:2 FTOH and transformation products using LC-MS/MS analysis, as described previously (Zhang et al., $2016 \mathrm{~b}$ ). Briefly, to capture volatile transformation products, $\mathrm{N}_{2}$ (about $1 \mathrm{~L}$ ) was used to purge the headspace for 3 min prior to removing the C18 cartridges from each bottle. Each C18 cartridge was eluted with $5 \mathrm{~mL}$ acetonitrile into a $20 \mathrm{~mL}$ vial. The stopper was pushed into each bottle prior to adding $50 \mathrm{~mL}$ acetonitrile. Afterwards, each bottle was crimp-sealed with a new stopper and shaken horizontally at $50{ }^{\circ} \mathrm{C}$ for 2 days at 200-250 rpm. The bottles were then centrifuged at $1000 \mathrm{rpm}$ for $30 \mathrm{~min}$ to collect the supernatant. Approximately 10 to $20 \mathrm{~mL}$ supernatant was filtered through nylon filters $(0.45 \mu \mathrm{m}$ pore $)$ into $20 \mathrm{~mL}$ glass vials and stored at $4{ }^{\circ} \mathrm{C}$ until LC-MS/MS analysis (first extract). The remaining sediment pellet was extracted a second time (second extract) in the same procedure except with $30 \mathrm{~mL}$ acetonitrile and $250 \mu \mathrm{L}$ of $5 \mathrm{M} \mathrm{NaOH}$ to recover sediment-bound 5:3 Acid and other transformation products (Zhao et al., 2013).

The first extract was further processed to recover organic particlebound 5:3 Acid by following the procedures described previously
(Zhao et al., 2013). Briefly, $0.4 \mathrm{~mL}$ first extract was added to $1.2 \mathrm{~mL}$ acetonitrile and mixed with $45 \mu \mathrm{L}$ of $1 \mathrm{M} \mathrm{NaOH}$ and 25-50 mg ENVI-Carb ${ }^{\mathrm{TM}}$ graphitized carbon in a $2 \mathrm{~mL}$ polypropylene tube. Each tube was incubated for $3-6$ h at $50{ }^{\circ} \mathrm{C}$ with $200 \mathrm{rpm}$ shaking in an orbital shaker and centrifuged at $2000 \mathrm{rpm}$ for $15 \mathrm{~min}$. Filtered supernatant was stored at $4{ }^{\circ} \mathrm{C}$ until LC-MS/MS analysis.

\subsection{LC-MS/MS quantitative analysis}

6:2 FTOH and potential transformation products were quantified by LC-MS/MS, as described previously (Tseng et al., 2014; Zhang et al., 2013), except on a Waters 2795 HPLC module coupled to a Quattro Micro triple quadrupole mass spectrometer (Milford, MA). Briefly, $20 \mu \mathrm{L}$ sample spiked with $50 \mu \mathrm{L}$ internal standard solution containing $10 \mathrm{ng}\left[1,2-{ }^{13} \mathrm{C}\right]$ PFHxA and $250 \mu \mathrm{g}\left[1,1,2,2-\mathrm{D} ; 3-{ }^{13} \mathrm{C}\right] 6: 2$ FTOH was injected onto an Agilent Zorbax RX-C8 column $(150 \mathrm{~mm} \times 2.1 \mathrm{~mm}$, $5 \mu \mathrm{m}$ particle size, pore size $80 \AA$, not end-capped, carbon loading $5.5 \%$ ). The mobile phase consisted of $0.15 \%$ acetic acid in Milli-Q water as solvent $A$ and $0.15 \%$ acetic acid in acetonitrile as solvent B. Detection limits ranged from 0.2 to $11 \mu \mathrm{g} / \mathrm{L}$ for all quantifiable PFASs. Detailed instrumental settings and parameters are shown in Table S2.

\subsection{DNA extraction, $P C R$ and 454 pyrosequencing}

For DNA extraction, $0.5 \mathrm{~g}$ sediment mixture was aseptically collected from the sample bottle after mixing well (volume ratio of sediment to river water was approximately 2:3) and extracted with FastDNA SPIN kit for soil (MPBIO, USA), according to the manufacturer's protocol. The quality and quantity of the DNA extract was determined by a SMA1000 UV spectrophotometer (Meriton, China) and confirmed by electrophoresis on a $1 \%$ agarose gel as previously described (Zhang et al., 2016a). The $\mathrm{OD}_{260} / \mathrm{OD}_{280}$ ratio ranged from 1.63 to 1.96 , and the DNA concentrations ranged from 79.7 to $186.4 \mu \mathrm{g} / \mathrm{mL}$.

The V3 region of the $16 \mathrm{~S}$ rRNA gene was amplified using a TC-25/H thermal cycler (Bio-Equip, Hangzhou, China), and the forward and reverse primers were 341F (5'-CCTACGGGAGGCAGCAG-3') and 518R (5'-ATTACCGCGGCTGCTGG-3'), respectively. The $50 \mu \mathrm{L}$ reaction medium consisted of $25 \mu \mathrm{L} 2 \times$ PCR Master Mix (Premix Taq ${ }^{\mathrm{TM}}$ Version 2.0, Takara), $0.5 \mu \mathrm{L}$ forward primer $(100 \mu \mathrm{M}), 0.5 \mu \mathrm{L}$ reverse primer $(100 \mu \mathrm{M}), 1 \mu \mathrm{L}$ DNA template, and $23 \mu \mathrm{L}$ sterilized Milli-Q water. The cycling parameters were as follows: preheat at $94^{\circ} \mathrm{C}$ for $5 \mathrm{~min}$, followed by 30 cycles of denaturation at $94{ }^{\circ} \mathrm{C}$ for $30 \mathrm{~s}$, hybridization at $55^{\circ} \mathrm{C}$ for $30 \mathrm{~s}$, and extension at $72{ }^{\circ} \mathrm{C}$ for $1 \mathrm{~min}$, and final extension at $72{ }^{\circ} \mathrm{C}$ for $10 \mathrm{~min}$. The PCR products were sent to Sangon Biotech Co., Ltd. (Shanghai, China; www.sangon.com) for sequencing by a Genome Sequencer FLX system (454 Life Sciences, Bradford, CT).

The DNA sequencing was run on an Illumina MiSeq platform and $250 \mathrm{bp} / 300 \mathrm{bp}$ paired-end reads were generated. Paired-end reads were merged by using Flash, and the low quality sequences were removed. Chimera was detected by UCHIME, and the resultant high quality sequences were grouped into operational taxonomic units, at a $97 \%$ sequence similarity threshold, using the UPARSE program in the QIIME (V1.6.0) software package. The total operational taxonomic units (OTUs) obtained for various treatments at day 0 and day 28 are listed in Table 2 with a 3\% cutoff and a minimum alignment length cutoff of $50 \mathrm{bp}$. The OTUs table was rarified to compute: 1) community richness estimators, Chao1 index and abundance coverage-based estimator (ACE); and 2) the community diversity estimator, Shannon index. Higher number of Chao1, ACE and Shannon indicate higher level of richness and diversity. These indices describe the similarities and differences among the different times and treatment samples. The taxonomic assignment to the genus level was performed with the Ribosomal Database Project (RDP) classifier with minimum confidence of $80 \%$. The identification at the species level was carried out by blast in NCBI database, with cutoff of $97 \%$. The heatmaps were visualized via $\mathrm{R}$ program (version 3.3.0) and Perl 5 (version 16, subversion 3). 


\section{Results and discussion}

\subsection{Comparison of low and high dosed 6:2 FTOH biotransformation in river sediment}

The biotransformation pathway of 6:2 FTOH in river sediment has been elucidated and well described (Zhao et al., 2013). Briefly, 5:3 Acid, PFHxA, PFPeA and PFBA were the major stable transformation products, whereas 5:2 sFTOH was the major intermediate product by day 28 and thereafter.

In this study, 6:2 FTOH biotransformation kinetics and the profile of major quantifiable transformation products are consistent with the previous findings (Kim et al., 2014, 2012; Zhao et al., 2013; Lewis et al., 2016). Current experiments showed that 6:2 FTOH in river sediment exhibited a half-life of $<3$ days, regardless of the initial doses. Approximately 80 mol\% 6:2 FTOH was converted within 3 days under both dosing conditions (Figs. S1 and S2 in the Supplemental material). However, there was difference in the profile of transformation products over time between the low and high 6:2 FTOH dosed conditions. For example, over $30 \mathrm{~mol} \%$ 6:2 FTCA was produced in the low 6:2 FTOH dosed condition on day 3 and decreased over time, suggesting the occurrence of rapid defluorination to 6:2 FTUCA (Fig. S3). Comparatively, only 12 mol\% 6:2 FTCA was produced in the high dosed condition by day 3 , and 6:2 FTCA accumulated over time with slower defluorination to 6:2 FTUCA, suggesting that 6:2 FTCA defluorination to 6:2 FTUCA may be the rate-limiting step in the high 6:2 FTOH dosed condition. This resulted in much lower molar yields of 5:2 sFTOH and other major stable transformation products, including 5:3 Acid, PFHxA, PFPeA, and PFBA (Table 1). The concentrations of 6:2 FTOH and its metabolites in the unexposed condition were quantified to be below detection limits.

The overall recovery of 6:2 FTOH and quantifiable transformation products compared with 6:2 FTOH applied at day 0 (mass balance expressed as mol\%) is also mostly comparable with Zhao et al. (2013a) from each experimental bottle, including sediment mixture, septum extract and C18 cartridge eluent. Over $28 \mathrm{~d}$ in the $5 \mathrm{mg} / \mathrm{L}$ live condition, the total recovery for $6: 2 \mathrm{FTOH}$ and its quantifiable transformation products averaged $97 \mathrm{~mol} \%$ with a range of 77 to $155 \mathrm{~mol} \%$, and in the $15 \mathrm{mg} / \mathrm{L}$ condition, the total recovery averaged $68 \mathrm{~mol} \%$ with a range of 38 to $100 \mathrm{~mol} \%$ (Figs. S1 and S2 in the Supplemental material). The higher than expected recovery (155 mol\%) on day 28 of the low $6: 2$ FTOH dosed condition was probably due to sacrificial sampling or instrumental variation. The loss of approximately $40-50 \mathrm{~mol} \%$ of initially applied 6:2 FTOH for the high dosed treatment at some time points was probably caused by 1 ) formation of sediment particle bound-residues with 6:2 FTOH and other transformation products, 2) undetectable or unquantifiable metabolites, or 3) lower efficiency in some C18 SPE cartridges (Kim et al., 2012; Liu et al., 2010b; Wang et al., 2009). Previous studies reported 71-88 mol\% recovery in aerobic sediment system, $77-87 \mathrm{~mol} \%$ recovery in aerobic soil system, $56-60 \mathrm{~mol} \%$ recovery in pure bacterial culture and $84-124 \%$ recovery in fungal culture (Kim et al., 2012; Liu et al., 2010b; Tseng et al., 2014; Wang et al., 2009; Zhao et al., 2013). Furthermore, recent studies demonstrate that 6:2 FTOH biotransformation can result in new metabolites lacking authentic analytical standards (Butt et al., 2014; Tseng et al., 2014). The recovery of 6:2 FTOH and its metabolites compared to previous reports demonstrates that the experimental system used in this study is valid for further microbial community analysis.

\subsection{Microbial community profile in the original sediment microcosm}

6:2 FTOH and those aforementioned major transformation products would impact the sediment microbial community. The phylogenetic composition of the microbial community in sediment microcosms exposed to 6:2 FTOH was obtained by 454 pyrosequencing of PCR-amplified bacterial 16S rRNA gene. A total of 99,062 sequences were obtained from a total of four samples that were clustered into 6107 operational taxonomic units (OTUs). Within the analyzed sequences, twenty-three total classified phyla in the domain Bacteria were identified in the river sediment mixture over time. On day 0, Proteobacteria was the predominant microorganism (18\%), followed by Chloroflexi (14\%), Verrucomicrobia (13\%), Firmicutes (3.4\%), Bacterioidetes $(2.4 \%)$, Actinobacteria (1.7\%) and Planctomycetes (1.3\%) (Fig. 1). Proteobacteria is one of the largest phyla and plays an important role in global chemical cycling and can be found in aerobic and anaerobic environments (Gupta, 2000; Marin, 2011; Michael et al., 2010). This group is divided into five classes on the basis of 16S rRNA gene sequence, including Alphaproteobacteria, Betaproteobacteria, Gammaproteobacteria, Deltaproteobacteria, and Epsilonproteobacteria (Gupta, 2000), which were all observed in the present study, and Alpha-, Beta- and Gammaproteobacteria have previously been shown to utilize aliphatic and aromatic compounds (Greer et al., 2010; Parales, 2010; van Beilen and Funhoff, 2007). For example, previous studies showed rapid aerobic biotransformation of 6:2 FTOH in 0.5-7 d towards production of 5:2 sFTOH and 5:2 Ketone by three Gammaproteobacteria: Pseudomonas oleovorans, Pseudomonas butanovora and Pseudomonas fluorescens DSM 8341 (Kim et al., 2014, 2012). From our genus profile analysis, Pseudomonas spp. were indeed present in the sediment mixture (Fig. 2). These findings indicate that Pseudomonas spp. may have played a role in the biotransformation of 6:2 FTOH in this study.

Microorganisms within the phylum Actinobacteria may have also played a role in 6:2 FTOH biotransformation. A strain belonging to this phylum, Mycobacterium vaccae JOB5, was previously shown to biotransform 6:2 FTOH to downstream transformation products, including 6:2 FTUCA and 5:2 ketone, with a half-life from 7 to $14 \mathrm{~d}$ (Kim et al., 2014). Moreover, species in the phylum Actinobacteria were found in oil contaminated sites and had specific genes for aliphatic hydrocarbon oxidation and desulfurization (Yoon et al., 2008). These results provide evidence that rapid 6:2 FTOH biotransformation may be the result of heterogeneous species microbial activities.

Table 1

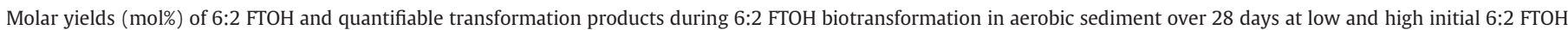
concentrations.

\begin{tabular}{|c|c|c|c|c|c|c|c|c|c|c|c|}
\hline & \multirow{2}{*}{$\frac{\% \mathrm{~mol}}{\text { Day }}$} & \multicolumn{5}{|c|}{ Low (5 mg/L initial 6:2 FTOH) } & \multicolumn{5}{|c|}{ High (15 mg/L initial 6:2 FTOH) } \\
\hline & & 0 & 3 & 7 & 14 & 28 & 0 & 3 & 7 & 14 & 28 \\
\hline & $6: 2 \mathrm{FTOH}$ & 100.00 & 25.83 & 21.80 & 24.71 & 19.30 & 100.00 & 19.08 & 17.18 & 9.87 & 2.45 \\
\hline \multirow[t]{5}{*}{ Transient Products } & 6:2 FTCA & - & 30.30 & 18.34 & 5.31 & - & - & 11.72 & 13.41 & 19.88 & - \\
\hline & $6: 2$ FTUCA & - & 9.81 & 10.36 & 8.65 & 0.05 & - & 4.24 & 20.39 & 9.82 & 4.18 \\
\hline & $5: 2$ ketone & - & 2.14 & 5.08 & 5.51 & 4.20 & - & 0.75 & 2.93 & 4.03 & 2.87 \\
\hline & $5: 2 \mathrm{sFTOH}$ & - & - & 11.68 & 19.08 & 72.76 & - & - & 4.53 & 12.63 & 27.58 \\
\hline & 5:3 Uacid & - & 1.25 & 0.61 & 3.24 & 1.04 & - & 0.49 & 0.30 & 3.04 & 0.41 \\
\hline \multirow[t]{4}{*}{ Stable Products } & 5:3 Acid & - & 0.64 & 4.23 & 6.26 & 23.18 & - & 0.23 & 5.07 & 9.51 & 9.58 \\
\hline & PFHxA & - & 0.57 & 2.79 & 5.67 & 25.77 & - & 0.40 & 1.53 & 3.48 & 11.01 \\
\hline & PFPeA & - & 0.73 & 0.05 & 1.06 & 5.34 & - & 0.36 & 0.04 & 0.32 & 2.03 \\
\hline & PFBA & - & - & 1.59 & 0.09 & 2.93 & - & 0.11 & 1.05 & 0.56 & 0.48 \\
\hline
\end{tabular}




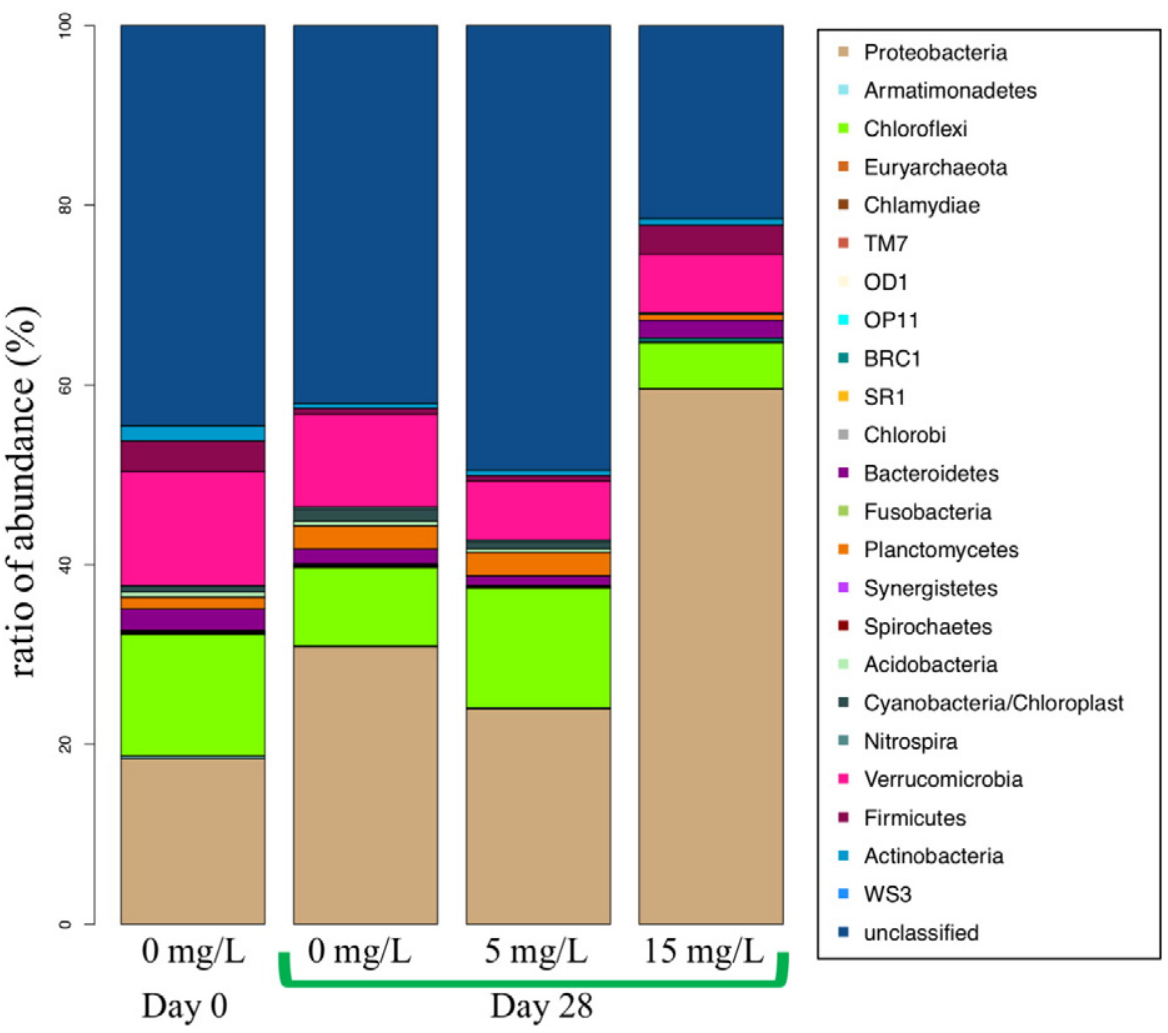

Fig. 1. Relative abundance of phylum in various 6:2 FTOH exposed treatments.

Other major phyla observed in this study may have also played important roles. For example, the phyla Verrucomicrobia and Planctomycetes were observed to co-occur in the sediment mixture over time and similar compartmentalization has been shown previously for these two phyla (Lee et al., 2009). Chloroflexi, Firmicutes and Bacteroidetes are commonly present in soil and river sediment (Hug et al., 2013; Liu et al., 2015) and have been shown to be associated with diesel- and hydrocarbon-contaminated soils (Sutton et al., 2013). Species within Chloroflexi and Firmicutes were also found to be enriched or could biotransform chlorinated solvents and organohalides (Krzmarzick et al., 2012, 2014). In addition, Firmicutes and Bacteroidetes were observed in a site contaminated with hexahydro-
Heatmap of phylum

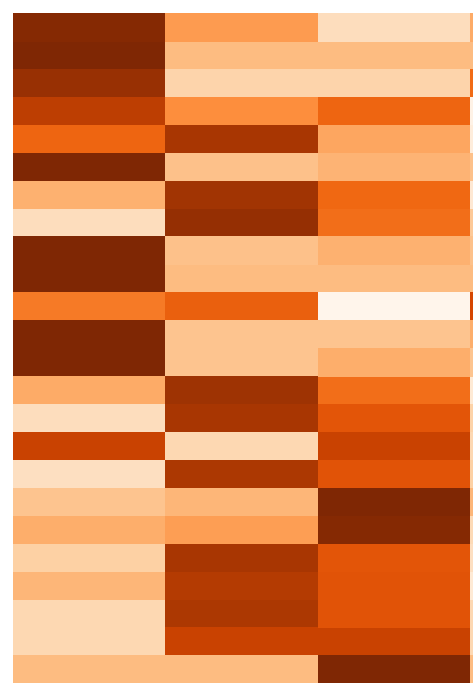

$0 \mathrm{mg} / \mathrm{L} \quad 0 \mathrm{mg} / \mathrm{L} \quad 5 \mathrm{mg} / \mathrm{L} \quad 15 \mathrm{mg} / \mathrm{L}$

Day 0

Day 28

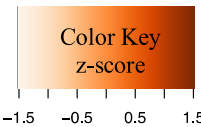

Heatmap of genera

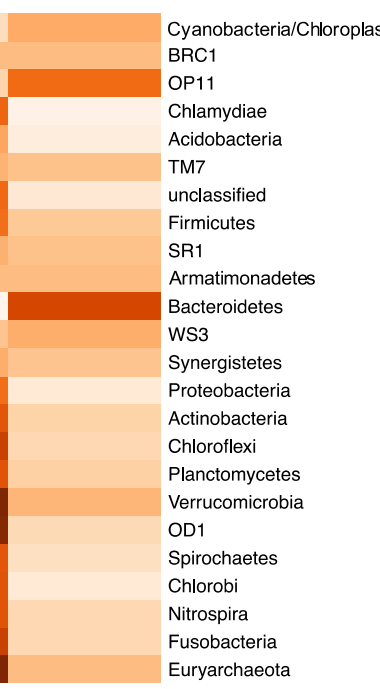

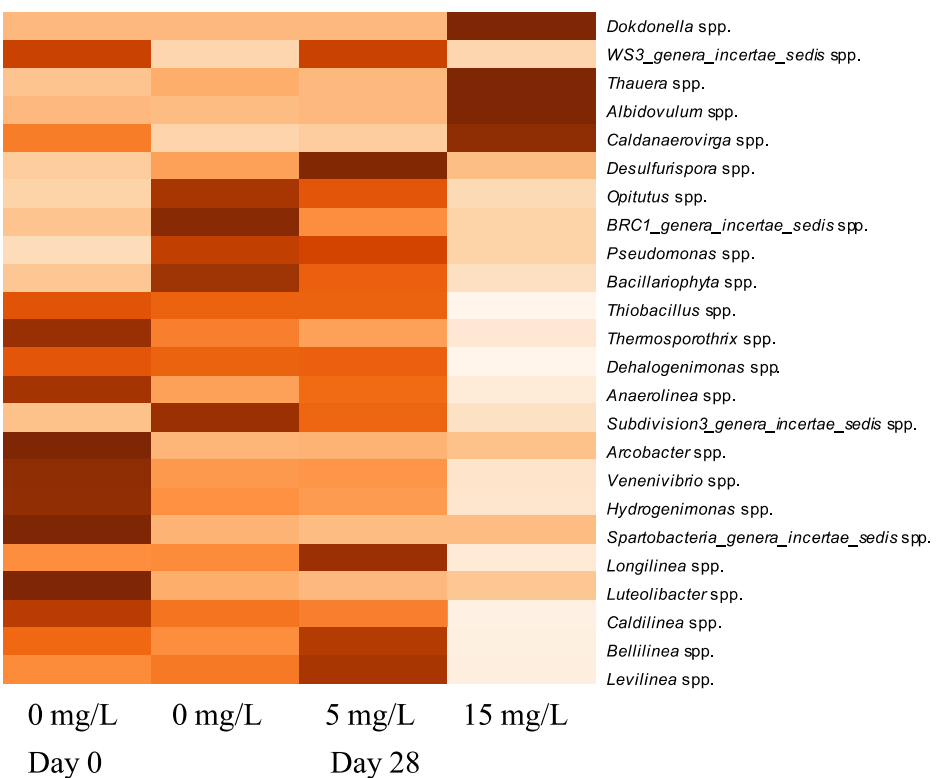

Fig. 2. Heatmap of phylum and selected genera. 
1,3,5-trinitro-1,3,5-triazine (RDX) (Cho et al., 2013, 2015, 2016; Cupples, 2013; Roh et al., 2009).

Other unknown microorganisms present in the sediment mixture may contribute to 6:2 FTOH biotransformation as well. A substantial portion (21-49\%) of the analyzed sequences were not assigned to any known phyla over time and across 6:2 FTOH initial doses (Fig. 1). Part of these unclassified sequences may belong to unrecognized or novel bacterial species with unknown functions (Rinke et al., 2013). Furthermore, other types of microorganisms, including eukaryotes and archaea, were not analyzed in this study. Archaea have been found to be highly abundant in diesel-contaminated soil samples (Sutton et al., 2013) and fungi, such as Phanerochaete chrysosporium, Gloeophyllum trabeum and Trametes versicolor, can biotransform 6:2 FTOH (Merino, 2016a). In addition, fungi isolated from AFFFs-contaminated site were observed to biotransform 6:2 FTOH towards 6:2 FTUCA and 5:3 Acid as the major transformation products (Merino, 2016a). Future research utilizing metagenomics and metatranscriptomics approaches is needed to investigate the impacts of 6:2 FTOH and other PFASs on the entire microbial community to elucidate the abundance, function and activity of sensitive and resistant genera (Yang et al., 2014). These methods can also be utilized to understand the necessary conditions needed for enriching and isolating promising microorganisms capable of PFASs biodegradation.

\subsection{Microbial community dynamics in the sediment microcosms exposed to 6:2 FTOH}

The diversity of the sediment microbial community was analyzed and indicated by OTUs, Chao1, ACE and Shannon indices (Table 2) (Hughes and Bohannan, 2004; Wang et al., 2012). The richness (Fig. S4) and Shannon Index diversity (Fig. S5) rarefaction curves suggest that there were clear richness differences between all conditions and that the current sequencing effort may not have fully captured the total microbial community due to the limitation of the target universal gene fragment (Eloe-Fadrosh et al., 2016). In the absence of 6:2 FTOH, the richness slightly decreased after the 28-day incubation. Saturated oxygen conditions, elevated temperatures, organic matter content and water content (Bell et al., 2013; Mackelprang et al., 2011) may have caused loss of sediment anaerobic microorganisms. In the presence of 6:2 FTOH and its transformation products, a dose-dependent reduction of richness was observed. For example, the Shannon index decreased from 6.10 to 3.66 while $6: 2$ FTOH initial concentrations increased from $5 \mathrm{mg} / \mathrm{L}$ to $15 \mathrm{mg} / \mathrm{L}$ (Table 2). Although only $2.45 \mathrm{~mol} \%$ 6:2 FTOH remained in the high dosed condition at day 28 , the decreasing richness may be due to the accumulation of 5:2 sFTOH, 5:3 Acid, and PFHxA, whose aquatic toxicological properties are not well understood. A recent study on the impact of PFAAs on the microbial community structure of sediment environment also revealed that higher concentrations of PFAAs reduced the community diversity and caused structural shifts (Sun et al., 2016). Similarly, in this study, only 307 same species $(5.0 \%$ of total species) were observed in both the 0 and $15 \mathrm{mg} / \mathrm{L} \mathrm{6:2} \mathrm{FTOH} \mathrm{con-}$ ditions by $28 \mathrm{~d}$, but 1349 same species ( $22 \%$ of total species) were found in both the 0 and $5 \mathrm{mg} / \mathrm{L}$ dosed bottles (Table 3 and Fig. S6). Comparatively, 1071 same species ( $18 \%$ of total species) were identified in the $0 \mathrm{mg} / \mathrm{L} \mathrm{6:2} \mathrm{FTOH} \mathrm{control} \mathrm{at} \mathrm{day} 0$ and 28, and this is likely a result of the incubation condition, as discussed previously (Bell et al., 2013; Mackelprang et al., 2011). As a result, three major factors may have

\section{Table 2}

Diversity and richness of sediment microbial community over time.

\begin{tabular}{lllll}
\hline Sample Condition & OTUs & Shannon & ACE & Chao1 \\
\hline Day 0 & 2870 & 6.65 & $10,477.20$ & 6596.76 \\
Day 28 0 mg/L 6:2 FTOH & 2713 & 6.44 & 7996.31 & 5947.28 \\
Day 28 $5 \mathrm{mg} / \mathrm{L} \mathrm{6:2} \mathrm{FTOH}$ & 2688 & 6.10 & 8437.61 & 5894.61 \\
Day 28 15 mg/L 6:2 FTOH & 1055 & 3.66 & 3030.82 & 2131.35
\end{tabular}

Table 3

Evolution of species number over time and across conditions.

\begin{tabular}{|c|c|c|c|c|c|}
\hline \multirow[t]{2}{*}{ Species } & & \multirow[t]{2}{*}{ Day $0^{\mathrm{a}}$} & \multicolumn{3}{|l|}{ Day $28^{a}$} \\
\hline & & & $0 \mathrm{mg} / \mathrm{L}$ & $5 \mathrm{mg} / \mathrm{L}$ & $15 \mathrm{mg} / \mathrm{L}$ \\
\hline Day $0^{\mathrm{a}}$ & & 2861 & & & \\
\hline \multirow[t]{3}{*}{ Day $28^{a}$} & $0 \mathrm{mg} / \mathrm{L}$ & 1071 & 2680 & & \\
\hline & $5 \mathrm{mg} / \mathrm{L}$ & 1078 & 1349 & 2635 & \\
\hline & $15 \mathrm{mg} / \mathrm{L}$ & 331 & 307 & 306 & 642 \\
\hline
\end{tabular}

${ }^{\text {a }}$ Numbers in bold type in columns 3 and 4, respectively, indicate the numbers of species at Day 0 and Day 28 in the sediment without 6:2 FTOH. Numbers in bold type in columns 5 and 6, respectively, indicate the numbers of species at Day 28 in the sediment exposed to 5 and $15 \mathrm{mg} / \mathrm{L}$ 6:2 FTOH. Numbers in regular type in column 3 indicate the numbers of same species in the various exposed sediment at Day 28 compared to the non-exposed sediment at Day 0. Numbers in regular type in column 4 indicate the numbers of same species in the 5 and $15 \mathrm{mg} / \mathrm{L}$ 6:2 FTOH exposed sediment at Day 28 compared to the non-exposed sediment at Day 28. The number in regular type in column 5 indicates the number of same species in the $15 \mathrm{mg} / \mathrm{L} \mathrm{6:2} \mathrm{FTOH} \mathrm{exposed} \mathrm{sediment} \mathrm{at} \mathrm{Day} 28 \mathrm{com}$ pared to the $5 \mathrm{mg} / \mathrm{L}$ 6:2 FTOH exposed sediment at Day 28 .

played selective roles on the sediment microbial community: 1) the incubation time, 2) the addition of 6:2 FTOH and its metabolites and 3) the dose of $6: 2 \mathrm{FTOH}$. In addition, the sediment particle bound-residues with 6:2 FTOH and other transformation products may also influence the microbial community structure via the impact of compound bioavailability (Zhao et al., 2013). These observations suggest that potential 6:2 FTOH bacterial degraders and tolerant strains existed in the sediment mixture and they began to dominate over time, particularly under high 6:2 FTOH dosed condition.

The genera-based heatmap further revealed variations in the abundance among treatments as a result of 6:2 FTOH and its transformation products (Fig. 2). In the unexposed condition at day 0 and 28 , the addition of mineral salts and aerobic condition influenced the distribution of the microbial community. For example, microorganisms belonging to Pseudomonas increased while those belonging to Luteolibacter decreased. Compared to the unexposed condition after the 28-day incubation, genera of Subdivision 3 genera incertae sedis, Opitutus and Bacillariophyta were sensitive to the biotransformation products of $5 \mathrm{mg} / \mathrm{L} \mathrm{6:2} \mathrm{FTOH}$ and were significantly reduced compared to day 0 . Interestingly, Bacillariophyta are diatoms and have been previously identified in freshwater, intertidal wetland, or marine sediments (Wang et al., 2012). On the contrary, the abundance of Desulfurispora, Longilinea, Bellilinea and Levilinea increased in the $5 \mathrm{mg} / \mathrm{L}$ 6:2 FTOH dosed condition but significantly reduced in the $15 \mathrm{mg} / \mathrm{L}$ dosed condition. Since the genera Opitutus, Desulfurispora, Levilinea, Longilinea, and Bellilinea contain anaerobic microorganisms, other processes within the microcosm may have also affected their growth, such as the influence of oxygen and the presence of ethanol. Previous studies have demonstrated that some anaerobic bacteria, such as sulfate-reducers, can survive oxygen exposure and have oxygen-reducing systems which enable them to survive in oxic or oxic-anoxic sediments (Cypionka, 2000; Hemp et al., 2015; Lemos et al., 2001). The genera Opitutus and Bellilinea were also found to increase in an aerobic-anaerobic pilot-scale aquifer system from undetectable levels to $5.3 \%$ and $8.3 \%$, respectively, after exposure to an ethanol blend containing ethanol, benzene and toluene (Ma et al., 2013). The increasing abundance of Dokdonella, Thauera, Albidovulum and Caldanaerovirga suggests these genera have higher tolerance to elevated concentrations of 6:2 FTOH and its transformation products. In general, the genus Thauera has been found in polluted soil and sediment due to its versatile metabolism (Liu et al., 2013; Yoo et al., 2009).

When comparing the microbial community profiles in the presence of different 6:2 FTOH concentrations with that in the original sediment, the structure was relatively stable at $5 \mathrm{mg} / \mathrm{L} 6: 2 \mathrm{FTOH}$, while significant shifts occurred at $15 \mathrm{mg} / \mathrm{L}$ 6:2 FTOH. The identification of potential 6:2 FTOH degraders, as well as polyfluoroalkyl acids producers and sensitive and resistant species suggests that the sediment microbial community followed the cooperative rule of "rock-scissors-paper" as demonstrated 
in microbial ecology (Morlon, 2012). Furthermore, the effort needed to biodegrade $15 \mathrm{mg} / \mathrm{L} 6: 2 \mathrm{FTOH}$ might have been beyond the original microbial community capacity and thus resulted in a significant shift in the community. Such high concentration may occur in some PFASs-contaminated locations (Moody and Field, 1999; Russell et al., 2015) and underlines the importance to understand the effects of PFASs, such as 6:2 FTOH and its major transformation products, on the microbial community. In this study, 6:2 FTOH placed selective pressure on the microbial community and its continuous biotransformation to other major transformation products complicated the microbial structure. To further isolate PFASs tolerant bacterial strains and identify functional genes, metagenomics analysis should be considered for future studies.

\section{Conclusions}

In this study, 6:2 FTOH was rapidly biotransformed with a half-life < 3 days, regardless of the initial doses. 6:2 FTOH and its transformation products played major roles in shaping sediment microbial community profiles and dynamics in a 6:2 FTOH dose-related manner, with higher dose $(15 \mathrm{mg} / \mathrm{L})$ promoted microbial enrichment in the sediment by day 28. Twenty-three total phyla within the domain Bacteria were identified in the river sediment mixture over time. The presence of 6:2 FTOH and accumulation of its major transient and stable transformation products impacted the microbial community abundance and diversity likely due to microbial responses needed to metabolize or detoxify these PFASs present in the sediment. These results, along with the addition of metagenomics and metatranscriptomics approaches in future studies, can provide insight for the isolation of potential microorganisms that can biodegrade PFASs. Our study on the characterization of sediment microbial community stability and dynamics will help predict changes in response to perfluoroalkyl and polyfluoroalkyl substances in the environment. Future work needs to identify the effect of individual transformation products on the microbial community, the genes involved in the biotransformation process using metagenomics approach, and the role of eukaryotic fungal community in response to PFASs presented in the environment.

\section{Acknowledgements}

We thank Zhen Hou and Junjun Yang for their assistance of sample collection and preparation. N. Merino received the Earth-Life Science Institute Origin of Life (EON) Postdoctoral Fellowship, which is supported by a grant from the John Templeton Foundation. The opinions expressed in this publication are those of the author(s) and do not necessarily reflect the views of the John Templeton Foundation. This study was financially supported by the National Natural Science Foundation of China (41471391, 40871214, 40830746), the Fok Ying Tung Education Foundation via the Ministry of Education, China (114043), the 111 Project (B14001), and Ministry of Education Program for New Century Excellent Talents in University (NCET-10-0200).

\section{Appendix A. Supplementary data}

Supplementary data to this article can be found online at http://dx. doi.org/10.1016/j.scitotenv.2016.09.214.

\section{References}

van Beilen, J.B., Funhoff, E.G., 2007. Alkane hydroxylases involved in microbial alkane degradation. Appl. Microbiol. Biotechnol. 74, 13-21.

Bell, T.H., Yergeau, E., Maynard, C., Juck, D., Whyte, L.G., Greer, C.W., 2013. Predictable bacterial composition and hydrocarbon degradation in Arctic soils following diesel and nutrient disturbance. ISME J. 7, 1200-1210.

Buck, R.C., Franklin, J., Berger, U., Conder, J.M., Cousins, I.T., de Voogt, P., Jensen, A.A., Kannan, K., Mabury, S.A., van Leeuwen, S.P.J., 2011. Perfluoroalkyl and polyfluoroalky substances in the environment: terminology, classification, and origins. Integr. Environ. Assess. Manag. 7, 513-541.
Butt, C.M., Muir, D.C.G., Mabury, S.A., 2014. Biotransformation pathways of fluorotelomerbased polyfluoroalkyl substances: a review. Environ. Toxicol. Chem. 33, 243-267.

Cho, K.-C., Fuller, M.E., Hatzinger, P.B., Chu, K.-H., 2016. Identification of groundwater microorganisms capable of assimilating RDX-derived nitrogen during in-situ bioremediation. Sci. Total Environ. 569-570, 1098-1106.

Cho, K.-C., Lee, D.G., Fuller, M.E., Hatzinger, P.B., Condee, C.W., Chu, K.-H., 2015. Application of $13 \mathrm{C}$ and $15 \mathrm{~N}$ stable isotope probing to characterize RDX degrading microbial communities under different electron-accepting conditions. J. Hazard. Mater. 297, $42-51$.

Cho, K.-C., Lee, D.G., Roh, H., Fuller, M.E., Hatzinger, P.B., Chu, K.-H., 2013. Application of $13 \mathrm{C}$-stable isotope probing to identify RDX-degrading microorganisms in groundwater. Environ. Pollut. 178, 350-360.

Cupples, A.M., 2013. RDX degrading microbial communities and the prediction of microorganisms responsible for RDX bioremediation. Int. Biodeterior. Biodegrad. 85, 260-270.

Cypionka, H., 2000. Oxygen respiration by Desulfovibrio species. Annu. Rev. Microbiol. 54, $827-848$

David, M.M., Cecillon, S., Warne, B.M., Prestat, E., Jansson, J.K., Vogel, T.M., 2015. Microbial ecology of chlorinated solvent biodegradation. Environ. Microbiol. 17, 4835-4850.

Delmont, T.O., Eren, A.M., Maccario, L., Prestat, E., Esen, Ö., Pelletier, E., LePaslier, D., SIMONET, P., Vogel, T., 2015. Reconstructing rare soil microbial genomes using in situ enrichments and metagenomics. Front. Microbiol. 6.

Dreyer, A., Ebinghaus, R., 2009. Polyfluorinated compounds in ambient air from ship-and land-based measurements in northern Germany. Atmos. Environ. 43 (8), 1527-1535.

Ellis, D.A., Martin, J.W., De Silva, A.O., Mabury, S.A., Hurley, M.D., Sulbaek Andersen, M.P., Wallington, T.J., 2004. Degradation of fluorotelomer alcohols: a likely atmospheric source of perfluorinated carboxylic acids. Environ. Sci. Technol. 38, 3316-3321.

Eloe-Fadrosh, E.A., Ivanova, N.N., Woyke, T., Kyrpides, N.C., 2016. Metagenomics uncovers gaps in amplicon-based detection of microbial diversity. Nat. Microbiol. 1, 15032.

Faust, K., Lahti, L., Gonze, D., de Vos, W.M., Raes, J., 2015. Metagenomics meets time series analysis: unraveling microbial community dynamics. Curr. Opin. Microbiol. 25, $56-66$.

Greer, C.W., Whyte, L.G., Niederberger, T.D., 2010. Microbial communities in hydrocarboncontaminated temperate, tropical, alpine, and polar soils. In: Timmis, K.N. (Ed.), Handbook of Hydrocarbon and Lipid Microbiology. Springer Berlin Heidelberg, Berlin, Heidelberg, pp. 2313-2328.

Gupta, R.S., 2000. The phylogeny of Proteobacteria: relationships to other eubacterial phyla and eukaryotes. FEMS Microbiol. Rev. 24, 367-402.

Hemp, J., Ward, L.M., Pace, L.A., Fischer, W.W., 2015. Draft genome sequence of Levilinea saccharolytica KIBI-1, a member of the Chloroflexi class anaerolineae. Genome Announc. 3.

Hsu, T., Joice, R., Vallarino, J., Abu-Ali, G., Hartmann, E.M., Shafquat, A., DuLong, C., Baranowski, C., Gevers, D., Green, J.L., Morgan, X.C., Spengler, J.D., Huttenhower, C., 2016. Urban transit system microbial communities differ by surface type and interaction with humans and the environment. mSystems 1.

Hug, L.A., Castelle, C.J., Wrighton, K.C., Thomas, B.C., Sharon, I., Frischkorn, K.R., Williams, K.H., Tringe, S.G., Banfield, J.F., 2013. Community genomic analyses constrain the distribution of metabolic traits across the Chloroflexi phylum and indicate roles in sediment carbon cycling. Microbiomedicine 1, 1-17.

Hughes, J., Bohannan, B.J., 2004. Application of ecological diversity statistics in microbial ecology. Mol. Microb. Ecol. Manual 2, 1321-1344.

Kim, M.H., Wang, N., Chu, K.H., 2014. 6:2 Fluorotelomer alcohol (6:2 FTOH) biodegradation by multiple microbial species under different physiological conditions. Appl. Microbiol. Biotechnol. 98, 1831-1840.

Kim, M.H., Wang, N., McDonald, T., Chu, K.-H., 2012. Biodefluorination and biotransformation of fluorotelomer alcohols by two alkane-degrading Pseudomonas strains. Biotechnol. Bioeng. 109, 3041-3048.

Kissa, E., 2001. Fluorinated Surfactants and Repellents. Dekker, New York, NY USA

Krzmarzick, M.J., Crary, B.B., Harding, J.J., Oyerinde, O.O., Leri, A.C., Myneni, S.C.B., Novak, P.J., 2012. Natural niche for organohalide-respiring Chloroflexi. Appl. Environ. Microbiol. 78, 393-401.

Krzmarzick, M.J., Miller, H.R., Yan, T., Novak, P.J., 2014. Novel Firmicutes group implicated in the dechlorination of two chlorinated xanthones, analogues of natural organochlorines. Appl. Environ. Microbiol. 80, 1210-1218.

Lee, K.C., Webb, R.I., Janssen, P.H., Sangwan, P., Romeo, T., Staley, J.T., Fuerst, J.A., 2009. Phylum Verrucomicrobia representatives share a compartmentalized cell plan with members of bacterial phylum Planctomycetes. BMC Microbiol. 9 (1)

Lemos, R.S., Gomes, C.M., Santana, M., LeGall, J., Xavier, A.V., Teixeira, M., 2001. The 'strict' anaerobe Desulfovibrio gigas contains a membrane-bound oxygen-reducing respiratory chain. FEBS Lett. 496, 40-43.

Lewis, M., Kima, M.H., Wang, N., Chu, K.H., 2016. Engineering artificial communities for enhanced FTOH degradation. Sci. Total Environ. 572, 935-942.

Liu, J., Mejia Avendaño, S., 2013. Microbial degradation of polyfluoroalkyl chemicals in the environment: a review. Environ. Int. 61, 98-114

Liu, J., Wang, N., Buck, R.C., Wolstenholme, B.W., Folsom, P.W., Sulecki, L.M., Bellin, C.A., 2010a. Aerobic biodegradation of C-14 6:2 fluorotelomer alcohol in a flow-through soil incubation system. Chemosphere 80, 716-723.

Liu, J., Wang, N., Szostek, B., Buck, R.C., Panciroli, P.K., Folsom, P.W., Sulecki, L.M., Bellin, C.A., 2010b. 6-2 Fluorotelomer alcohol aerobic biodegradation in soil and mixed bacterial culture. Chemosphere 78, 437-444.

Liu, B., Frostegård, Å., Shapleigh, J.P., 2013. Draft genome sequences of five strains in the genus Thauera. Genome Announc. 1.

Liu, S., Ren, H., Shen, L., Lou, L., Tian, G., Zheng, P., Hu, B., 2015. pH levels drive bacterial community structure in sediments of the Qiantang River as determined by 454 pyrosequencing. Front. Microbiol. 6, 285. 
Lu, X., Chen, C., Zhang, S., Hou, Z., Yang, J., 2013. Concentration levels and ecological risks of persistent organic pollutants in the surface sediments of Tianjin coastal area, China. Sci. World J. 2013 (10), 417435

Ma, J., Nossa, C.W., Xiu, Z., Rixey, W.G., Alvarez, P.J.J., 2013. Adaptive microbial population shifts in response to a continuous ethanol blend release increases biodegradation potential. Environ. Pollut. 178, 419-425.

Mackelprang, R., Waldrop, M.P., DeAngelis, K.M., David, M.M., Chavarria, K.L., Blazewicz, S.J., Rubin, E.M., Jansson, J.K., 2011. Metagenomic analysis of a permafrost microbial community reveals a rapid response to thaw. Nature 480, 368-371.

Marin, I., 2011. Proteobacteria. In: Gargaud, M., Amils, R., Quintanilla, J.C., Cleaves, H.J., Irvine, W.M., Pinti, D.L., et al. (Eds.), Encyclopedia of Astrobiology. Springer Berlin Heidelberg, Berlin, Heidelberg, p. 1350.

Merino, N., 2016a. Fungal Biotransformation of Polyfluoroalkyl Substances: Identification of Growth Substrates for Favorable Biotransformation Pathways. Ph.D. Dissertation, University of California, Los Angeles, Los Angeles, CA http://eprints.cdlib.org/uc/ item/9hq2n6g2.

Merino, N., Qu, Y., Deeb, R.A., Hawley, E.L., Hoffmann, M.R., Mahendra, S., 2016b. Degradation and removal methods for perfluoroalkyl and polyfluoroalkyl substances in water. Environ. Eng. Sci. 33, 615-649.

Michael, T., John, M., Jack, P., December 27, 2010. Brock Microbiology of Microorganism. 13 edition. Benjamin Cummings.

Moody, C.A., Field, J.A., 1999. Determination of perfluorocarboxylates in groundwater impacted by fire-fighting activity. Environ. Sci. Technol. 33, 2800-2806.

Morlon, H., 2012. Microbial cooperative warfare. Science 337, 1184-1185.

Parales, R.E., 2010. Hydrocarbon degradation by Betaproteobacteria. In: Timmis, K.N. (Ed.), Handbook of Hydrocarbon and Lipid Microbiology. Springer Berlin Heidelberg, Berlin, Heidelberg, pp. 1715-1724.

Rinke, C., Schwientek, P., Sczyrba, A., Ivanova, N.N., Anderson, I.J., Cheng, J.-F., Darling, A., Malfatti, S., Swan, B.K., Gies, E.A., Dodsworth, J.A., Hedlund, B.P., Tsiamis, G., Sievert, S.M., Liu, W.-T., Eisen, J.A., Hallam, S.J., Kyrpides, N.C., Stepanauskas, R., Rubin, E.M. Hugenholtz, P., Woyke, T., 2013. Insights into the phylogeny and coding potential of microbial dark matter. Nature 499, 431-437.

Ritter, S.K., 2015. The shrinking case for Fluorochemicals. Chem. Eng. News 93, 27-29.

Roh, H., Yu, C.-P., Fuller, M.E., Chu, K.-H., 2009. Identification of hexahydro-1,3,5-trinitro1,3,5-triazine-degrading microorganisms via $15 \mathrm{~N}$-stable isotope probing. Environ. Sci. Technol. 43, 2505-2511.

Russell, M.H., Himmelstein, M.W., Buck, R.C., 2015. Inhalation and oral toxicokinetics of 6: 2 FTOH and its metabolites in mammals. Chemosphere 120, 328-335.

Serex, T., Anand, S., Munley, S., Donner, E.M., Frame, S.R., Buck, R.C., Loveless, S.E., 2014 Toxicological evaluation of 6:2 fluorotelomer alcohol. Toxicology 319, 1-9.

Sinclair, J.L., Ghiorse, W.C., 1989. Distribution of aerobic bacteria, protozoa, algae, and fungi in deep subsurface sediments. Geomicrobiol J. 7, 15-31.

Sun, Y., Wang, T., Peng, X., Wang, P., Lu, Y., 2016. Bacterial community compositions in sediment polluted by perfluoroalkyl acids (PFAAs) using Illumina high-throughput sequencing. Environ. Sci. Pollut. Res. 23, 10556-10565.

Sutton, N.B., Maphosa, F., Morillo, J.A., Abu, A.-S.W., Langenhoff, A.A.M., Grotenhuis, T., Rijnaarts, H.H.M., Smidt, H., 2013. Impact of long-term diesel contamination on soil microbial community structure. Appl. Environ. Microbiol. 79, 619-630.

Tian, Z., Kim, S.-K., Shoeib, M., Oh, J.-E., Park, J.-E., 2016. Human exposure to per- and polyfluoroalkyl substances (PFASs) via house dust in Korea: implication to exposure pathway. Sci. Total Environ. 553, 266-275.
Tseng, N., Wang, N., Szostek, B., Mahendra, S., 2014. Biotransformation of 6:2 fluorotelomer alcohol (6:2 FTOH) by a wood-rotting fungus. Environ. Sci. Technol. 48, 4012-4020.

Vaishampayan, P.A., Kuehl, J.V., Froula, J.L., Morgan, J.L., Ochman, H., Francino, M.P., 2010 Comparative metagenomics and population dynamics of the gut microbiota in mother and infant. Genome Biol. Evol. 2, 53-66.

Wang, Z., Cousins, I.T., Scheringer, M., Buck, R.C., Hungerbühler, K., 2014. Global emission inventories for C 4-C 14 perfluoroalkyl carboxylic acid (PFCA) homologues from 1951 to 2030. Part I: production and emissions from quantifiable sources. Environ. Int. 70, pp. 62-75.

Wang, Y., Sheng, H.-F., He, Y., Wu, J.-Y., Jiang, Y.-X., Tam, N.F.-Y., Zhou, H.-W., 2012. Comparison of the levels of bacterial diversity in freshwater, intertidal wetland, and marine sediments by using millions of Illumina tags. Appl. Environ. Microbiol. 78, 8264-8271.

Wang, N., Szostek, B., Buck, R.C., Folsom, P.W., Sulecki, L.M., Gannon, J.T., 2009. 8-2 fluorotelomer alcohol aerobic soil biodegradation: pathways, metabolites, and metabolite yields. Chemosphere 75, 1089-1096.

Yang, Y., Quensen, J., Mathieu, J., Wang, Q., Wang, J., Li, M., Tiedje, J.M., Alvarez, P.J., 2014 Pyrosequencing reveals higher impact of silver nanoparticles than $\mathrm{Ag}+$ on the microbial community structure of activated sludge. Water Res. 48, 317-325.

Yao, Y., Chang, S., Sun, H., Gan, Z., Hu, H., Zhao, Y., Zhang, Y., 2016. Neutral and ionic perand polyfluoroalkyl substances (PFASs) in atmospheric and dry deposition samples over a source region (Tianjin, China). Environ. Pollut. 212, 449-456.

Yoo, S.-H., Weon, H.-Y., Anandham, R., Kim, B.-Y., Hong, S.-B., Jeon, Y.-A., Koo, B.-S., Kwon, S.-W., 2009. Dokdonella soli sp. nov., a gammaproteobacterium isolated from soil. Int. J. Syst. Evol. Microbiol. 59, 1965-1968.

Yoon, J., Matsuo, Y., Adachi, K., Nozawa, M., Matsuda, S., Kasai, H., Yokota, A., 2008. Description of Persicirhabdus sediminis gen. nov., sp. nov., Roseibacillus ishigakijimensis gen. nov., sp. nov., Roseibacillus ponti sp. nov., Roseibacillus persicicus sp. nov. Luteolibacter pohnpeiensis gen. nov., sp. nov. and Luteolibacter algae sp. nov., six marine members of the phylum 'Verrucomicrobia', and emended descriptions of the class Verrucomicrobiae, the order Verrucomicrobiales and the family Verrucomicrobiaceae. Int. J. Syst. Evol. Microbiol. 58, 998-1007.

Yuan, G., Peng, H., Huang, C., Hu, J., 2016. Ubiquitous occurrence of fluorotelomer alcohols in eco-friendly paper-made food-contact materials and their implication for human exposure. Environ. Sci. Technol. 50, 942-950.

Zhang, S., Hou, Z., Du, X., Li, D., Lu, X., 2016a. Assessment of biostimulation and bioaugmentation for removing chlorinated volatile organic compounds from groundwater at a former manufacture plant. Biodegradation 1-14.

Zhang, S., Lu, X., Wang, N., Buck, R.C., 2016b. Biotransformation potential of 6:2 fluorotelomer sulfonate (6:2 FTSA) in aerobic and anaerobic sediment. Chemosphere 154, 224-230.

Zhang, S., Szostek, B., McCausland, P.K., Wolstenholme, B.W., Lu, X., Wang, N., Buck, R.C. 2013. 6:2 and 8:2 fluorotelomer alcohol anaerobic biotransformation in digester sludge from a WWTP under methanogenic conditions. Environ. Sci. Technol. 47 4227-4235.

Zhao, L., Folsom, P.W., Wolstenholme, B.W., Sun, H., Wang, N., Buck, R.C., 2013. 6:2 Fluorotelomer alcohol biotransformation in an aerobic river sediment system. Chemosphere 90, 203-209. 